\title{
Theoretical Model of Fundamental Entrepreneurial Competencies
}

\author{
Käthe Schneider ${ }^{1}$, Carlos Albornoz ${ }^{2}$ \\ ${ }^{1}$ Faculty of Social and Behavioural Sciences, Friedrich-Schiller-Universitaet Jena, Jena, Germany \\ ${ }^{2}$ Facultad de Economía y Negocios, Universidad del Desarrollo, Santiago de Chile, Chile
}

Email address:

k.schneider@uni-jena.de (K. Schneider), calbornoz@udd.cl (C. Albornoz)

\section{To cite this article:}

Käthe Schneider, Carlos Albornoz. Theoretical Model of Fundamental Entrepreneurial Competencies. Science Journal of Education. Vol. 6, No. 1, 2018, pp. 8-16. doi: 10.11648/j.sjedu.20180601.12

Received: January 24, 2018; Accepted: February 6, 2018; Published: February 27, 2018

\begin{abstract}
Scientific interest in teaching entrepreneurial competencies has increased in the last few years. Thereby studies have examined above all personal tools, including skills and knowledge. However, besides focusing on educational programs for context-specific entrepreneurial competencies, it is essential to understand general competencies that enable an entrepreneur to master demands of varying challenges and contexts. Despite a growing body of literature in the field of entrepreneurial competencies, there still seems to be uncertainty regarding general entrepreneurial competencies. As a consequence of its research focus, the objective of this study is to understand general entrepreneurial competencies. To study these general competencies, new paradigms of human action should be brought into discussion. It is concluded that there is a relationship between the self and general entrepreneurial key behavior which has still not been covered by the literature. The overall goal of this study is thus to propose a model of general entrepreneurial competencies. An entrepreneurial competency model is proposed that gives insight about the key behavior of recognizing/producing and exploiting entrepreneurial opportunity which a successful entrepreneur should be able to demonstrate, and a person's underlying characteristics. The underlying characteristics consist of the self and personal tools. The self comprises the self-as-subject, the ego as a meaningmaking process, and the self-as-object, with dispositional traits, characteristic adaptations and identity. Personal tools include skills and knowledge. The structural model has been enriched with a developmental dimension as the entrepreneurial ego gradually becomes more complex and associated entrepreneurial behaviors and skills are increasingly practiced. Clarifying these theoretical links between the self and entrepreneurial core challenges may contribute to more effective design of fundamental entrepreneurship education programs and to addressing a wider range of educational issues, e.g., developing scientifically-supported educational models to increase the number of successful entrepreneurs.
\end{abstract}

Keywords: Entrepreneurial Competencies, Self, Fundamental Competencies, Ego Development, Meaning Making, Entrepreneurial Identity

\section{Introduction}

The increasing importance of entrepreneurship research over the last few decades is the result of a profound transformation in the business environment that is characterized by rapidly changing contexts. Continuing changes in the business context necessitate continuous learning. As a consequence, the need for and supply of entrepreneurial education has grown exponentially.

While entrepreneurial success is a complex phenomenon that interacts with various factors [38], such as e.g. personal competencies, socio-cultural and economic factors, education in entrepreneurship should consider the environment, but focus on individual competencies [38]. In the following, Entrepreneurship Education is understood to provide tools for aspiring, nascent, and practicing entrepreneurs to launch new and improve or grow existing businesses [8]. To develop educational and training programs that can increase entrepreneurial success, competencies should be identified that can further entrepreneurial success.

Scientific interest in teaching entrepreneurial competencies has increased in the last few years $[37,9]$. Thereby studies have examined above all personal tools, including skills and knowledge. However, besides focusing on educational 
programs for context-specific entrepreneurial competencies, it is essential to understand general competencies that enable an entrepreneur to master demands of varying challenges and contexts. Despite a growing body of literature in the field of entrepreneurial competencies, there still seems to be uncertainty regarding general entrepreneurial competencies [e.g. 7, 29, 35]. As a consequence of its research focus, the objective of this study is to understand general entrepreneurial competencies.

To study these general competencies, new paradigms of human action should be brought into discussion. It is concluded that there is a relationship between the self and general entrepreneurial key behavior which has still not been covered by the literature. The overall goal of this study is thus to propose a model of general entrepreneurial competencies.

Clarifying these theoretical links between the self and entrepreneurial core challenges may contribute to more effective design of fundamental entrepreneurship education programs and to addressing a wider range of educational issues, e.g., developing scientifically-supported educational models to increase the number of successful entrepreneurs.

\section{Literature Review}

In recent years there has been increased scientific interest in the identification of entrepreneurial competencies [37,9].

To define the concept of competency, a definition proposed by Boyatzis [5, 4] has been selected. According to him, competency is an underlying set of personal characteristics that facilitate superior performance [e.g. 5, 4]. Boyatzis [4 p. 6] concluded that competency is "organized around an underlying construct" that he called "intent." "The behaviors are alternate manifestations of the intent, as appropriate in various situations or times." [4 p. 6] The observed behavior is the action. According to Venkataraman [47] entrepreneurship can be regarded as the discovery, evaluation and exploitation of future goods and services.

To identify the underlying characteristics that facilitate superior performance, it is necessary to understand the target actions in which the performance should manifest itself. Mitchelmore and Rowley [35 p. 100] characterize the observed targeted entrepreneurial behavior, entrepreneurial action consisting of: "identification and definition of a viable market niche," "development of products or services appropriate to the firm's chosen market niche/product innovation," "idea generation," "environmental scanning," "recognizing and envisioning taking advantage of opportunities" and "formulating strategies for taking advantage of opportunities."

More generally, drawing on Shane and Venkataraman [43], entrepreneurial key behavior can be described as oriented to discovering and exploiting opportunities. An opportunity is a favorable or advantageous situation, a chance involving the rare possibility of being able to recognize a specific situation that under other conditions is imperceptible or is linked to disadvantages [43]. Perception of the situation and recombination of resources can create subjective or also objective value. Shane and Venkataraman [43] posit that discovering and exploiting opportunities are the unique characteristics of entrepreneurship. "Although the discovery of an opportunity is a necessary condition for entrepreneurship, it is not sufficient. Subsequent to this discovery of an opportunity, a potential entrepreneur must decide to exploit the opportunity." [43 p. 222]

From the individual person's perspective, business opportunities can be understood as interpretations, mental dialogues that adults hold about the world where they live. If a constructivist paradigm is adopted, opportunities are meaningful to the adult not because of the opportunity's objective conditions, but because of the particular interaction between an adult's previous experience, plans and objectives and the environment where she lives. A business opportunity can be understood as a personal narrative that someone develops concerning benefits of a situation for her and society [45], which then gives meaning to the opportunity. This perception motivates specific actions to capture the opportunity. Entrepreneurs, as living systems, are structured and determined systems, and as such they make choices and decisions, and nothing external to them can determine what they will do [30]. An opportunity does not exist outside the entrepreneur's head.

The literature includes many studies of entrepreneurial competencies. These studies show that underlying characteristics include components such as knowledge [33], attitudes [e.g. 27], motives [e.g. 40], skills [e.g. 3, 28, 46], characteristic adaptations [27] and traits $[6,12,22,27,37$, 40].

Only a few studies are based on theoretical models of underlying characteristics [e.g. 5, 44]. One approach modeling the underlying characteristics that promote entrepreneurial performance was developed by Boyatzis, who drew on McClelland's personality theory. According to McClelland [32], the personality is comprised of relationships among a person's unconscious motives, selfschema and observed behavioral patterns. Boyatzis' competency model [4, 5 p. 8] is " $\ldots$ an integrated system diagram that showed concentric circles": Near the center of the circle model are circles representing motives and trait dispositions. The middle circle is for values and self-images. Skills form the outer circle. The circle for skills represents observed behaviors or actions. While externally located characteristics on the "surface" are more visible and easiest to develop, characteristics in the interior, traits and motives, the "core personality," are hidden and most difficult to develop [44].

Previous models of entrepreneurial competencies focus more on the circles of dispositional traits, motives, characteristic adaptations, observable skills and behaviors [e.g. 3, 6, 22, 27, $28,40,46]$. In contrast, recent studies seek to establish the circle of identity that refers to the second circle in Boyatzis' model, in order to understand the transition processes of becoming successful entrepreneurs [e.g. 39]. The identity conceptualized as one's self-concept that changes over time and across roles 
[15] affects the transition process of becoming a successful entrepreneur: the roles an entrepreneur occupies and that are closely related to her identity lead to differential exposure to business opportunities and may influence entrepreneurial performance in different ways [15].

To summarize, most of the studies classifying entrepreneurial competencies as an underlying set of personal characteristics that facilitates superior performance are mainly inductively based and represent different categories of entrepreneurial competencies, such as traits and motives, self-concepts, and values, skills and knowledge, and recently as well identity.

Theoretical perspectives of leadership development are well suited to shed more light on underlying general competencies: According to Day, Harrison and Halpin [10], leadership development occurs on multiple levels, ranging from observable skills and behaviors to identity to ways of creating meaning. Because meaning making has a fundamental influence on any observable behavior [10, 14], it is assumed that meaning making exerts influence on key entrepreneurial behavior.

In the following an entrepreneurial competency model is proposed that provides insight about the key behavior which a successful entrepreneur should be able to demonstrate, and the general underlying characteristics of a person which result in the intended behavior. The framed model is based using the constructive adult development perspectives of ego-development [24] and self-development [18], combined with the competency-based approach. Each theoretical paradigm brings to the discussion a rich dimension to depict how fundamental entrepreneurial competencies can be understood.

\section{Development of the Model}

\subsection{Theoretical Foundation}

In order to advance our understanding of the general underlying entrepreneurial personal characteristics of key entrepreneurial behavior, the need is highlighted to integrate the self as a meaning-making system. It is assumed that underlying characteristics of key entrepreneurial behavior are formed by specific configurations of the self.

The self is characterized by the "self-as-subject" ("I"=Iself) and the "self-as-object" ("Me"=Me-self) [17]. The duplex self is both "I" (process), and "Me" (product) [17]. The "self-as-subject," the "I," or "Ego", represents above all a process of meaning making $[24,31]$. The "I" or "Ego" knows and creates the "Me" [31]. The "self-as-object" or the "Me" stands for the synthesis of experiences, the created meanings as the concept of the self that can be recognized by the "I" $[31,24]$.

Referring to the "self-as-subject," the "Ego" "... provides the frame of reference that structures one's world and within which one perceives the world ..." [24 pp. 9-10]. A frame of reference is a "meaning perspective" through which a person structures and filters sense impressions, assumptions and expectations [34 p. 16].

According to Loevinger [24], the "Ego" involves a person's processes of subjectively imposing a frame of reference on life experiences to create meaning. The "Ego" is related to four domains: character, cognitive style, interpersonal style and conscious preoccupations [24]. In this view, structures and processes of cognition, impulse control and character, interpersonal style and conscious preoccupations take a central role that leads to grasping and exploiting business opportunities. Character refers to impulse control, and to dealing with own standards. Cognitive style is related to the question of how a person thinks and reasons about herself and the world. Interpersonal style stands for one's attitude toward interpersonal relationships, preferred types of relationships, understandings of relationships and the way one deals with other people. Conscious preoccupations represent conscious thoughts, such as on the purpose of life and the ends a person is moving towards. Because the "Ego" produces the "Me," or identity, ego-development has an impact on identity. As the ego and entrepreneurial self-concept (identity) develop, this development regulates impulse control, interpersonal style, conscious preoccupations and cognitive style.

The developmental process includes nine developmental stages that are manifested in structural and content-related changes of the four domains [24]. These nine stages are: E1: The first stage; E2: Impulsive Stage, E3: Self-Protective Stage, E4: Conformist Stage, E5: Self-Aware Stage, E6: Conscientious Stage, E7: Individualistic Stage, E8: Autonomous Stage, and E9 Integrated Stage. The

Self-Protective Stage (E3) is a Pre-Conformist Stage [36] that is relatively rare in adult populations. The next two stages - Conformist and Self-Aware (E4; E5) - are considered conformist stages [36]. The final four stages Conscientious, Individualistic, Autonomous and Integrated ( $\geq$ E6) - are regarded as post-conformist [36].

Pre-conformist Stage: Persons on this level are characterized above all by a reference frame of immediate need satisfaction, due to which their actions are above all determined by needs. Their cognitive operations are of a predominantly concrete nature, so that inner states can scarcely be perceived and reflected on. Motivation to satisfy own needs determines their interpersonal style.

Conformist Stage: On this level of ego-development the reference frame of interpersonal acceptance is central. The values and expectations of other reference persons determine a person's actions. The self is perceived and reflected with the aid of reference group stereotypes. Social acceptance, normorientation and social desirability determine social interaction.

Post-Conformist Stage: The reference frame that dominates on this level of development is that of self-realization. Cognitive operations are of a complex nature, in which complex states can be perceived and reflected. Mutuality, or reciprocity, is the central principle of interaction.

In the following, stages E4-E7 which can most often be found within the population are described in more detail: 
Table 1. Stages of ego-development [adapted from 26 p. 5].

\begin{tabular}{lllll}
\hline & Character & Cognitive style & Interpersonal style & Conscious preoccupations \\
\hline E4 Conformist & - Respect for rules & - Conceptual simplicity & - Cooperative & - Appearances \\
& & & - Loyal & - Behavior \\
E5 Self-Aware (expert) & - Exceptions allowable & - Multiplicity & - Helpful & - Feelings \\
& & - Self-aware & - Problems \\
& & & - Adjustment \\
E6 Conscientious (achiever) & - Self-evaluated standards & - Formal operations & - Intense & - Motives \\
& - Self-critical & & - Responsible & - Traits \\
& & & - Achievements \\
E7 Individualist & - Tolerant & - Relativism & - Mutual & - Individuality \\
& & & - Development \\
\hline
\end{tabular}

Conformist Stage (E4) Conventional standards, a need for belonging, rule-bound and stereotypical style of thinking and acting, as well as conceptual simplification are chief characteristics of this stage $[26,16]$. A person in this stage wants social approval. They accept the values, norms and attitudes of their group without criticizing or questioning them. Their self is defined and generated by the expectations and values of in-group members. Conformists comply with rules and are beginning to internalize and follow them automatically. They condemn norms, values and attitudes different from those of their group. [26, 16]

Persons in the Self-Aware Stage (E5) This more complex mental state allows people to see multiple possibilities and to start examining and reflecting on themselves. The theme of opportunities is becoming important. Persons in this stage are able to differentiate themselves from others and to express the personality they are starting to discover, including their needs. An increase in self-awareness and appreciation of multiple possibilities in situations are chief characteristics of this stage. $[26,16]$

Conscientious Stage (E6) is characterized by formal operations and conceptual complexity [16]. Self-evaluated standards, perceived and displayed conceptual complexity, and value achievement form the ego [16]. Central elements of a conscience are developed with long-term self-evaluated goals, differentiated self-criticism and a strong sense of responsibility. The interpersonal style is characterized by mutuality: Persons are able to see matters from the other perspectives and to value others for who they are, independently of their own view. [26, 16]

In the next stage, the Individualist Stage (E7), people gain a sense of individuality and relativism. They recognize the subjectivity of different viewpoints. They can perceive how much their values and worldviews have been influenced by the environments in which they grew up. Their own underlying assumptions and those of others become a focus and can be recognized and questioned. Situations and people come to be grasped more strongly as changeable and less as static. This stage allows individuals to look at systems of thought or organizations. [26, 16]

Underlying characteristics of key entrepreneurial behavior are shaped by these specific configurations of the self. It is proposed that ego-development goes along with the development of key entrepreneurial behavior.

\subsection{Fundamental Underlying Personal Characteristics of Key Entrepreneurial Behaviors}

Building on the contributions of Shane and Venkataraman [43], the entrepreneurial key behavior of "discovering" opportunities is differentiated according to the actions of discovering and creating. The complex patterns of entrepreneurial behaviors are related to the broad concept of ego-development and propose that the entrepreneurial self interacts with the entrepreneurial key behavior of discovering or respectively creating and exploiting entrepreneurial opportunities. The study concludes that the conformist stage of ego-development is relevant to discovering, and the postconformist stage to creating entrepreneurial opportunities.

Eckhardt and Shane [11] define "entrepreneurial opportunities as situations in which new goods, services, raw materials, markets and organizing methods can be introduced through the formation of new means, ends, or means-ends relationships." In the theory of entrepreneurship it is distinguished between Schumpeterian opportunity [42, 41] and Kirznerian opportunity [21]. Schumpeterian [42, 41] opportunity is characterized by its innovative character, and on the acting person's side by the proactive element of creating opportunity which destroys market equilibrium, while for Kirzner [21] discovery of an opportunity for more imitative behavior contributes to market equilibrium [cf. also 13 p. 6]. Market equilibrium refers to a market situation in which quantity supplied is equal to quantity demanded. Supply is the amount of a good that manufacturers will produce at a given price. Demand is the quantity of a good that consumers will buy at a given price. Kirzner [21] fundamentally viewed entrepreneurship as the recognition of a business opportunity and an entrepreneur as a person alert to opportunities. Entrepreneurs identify unnoticed opportunities and create businesses starting from them. In the process of creating new businesses, entrepreneurs restore market equilibrium. As implied by Kirzner, entrepreneurs notice and exploit opportunities that exist independently of the entrepreneur. Entrepreneurs create products for existing markets, and their main challenge is to link demand and supply, finding possibilities for this through research. Schumpeter [42], on the other hand, understood entrepreneurship as creative destruction of market equilibrium. 
Schumpeter $[42,41]$ viewed the entrepreneur as an innovator. The entrepreneur creates a radical innovation that destroys an old market equilibrium and replaces it with a new one. With regard to Schumpeter and Kirzner, Grichnik [13 p. 3] locates entrepreneurial opportunity on a continuum, on a scale with two endpoints to represent innovation: Grichnik [13 p. 4, cf. also 23 p. 458] sees the endpoints in "discovering" and "creating" opportunities [13 p. 4, 23 p. 458].

The actions of discovering and creating opportunities involve different knowledge and cognitive process stages. Based on a taxonomy of Anderson and Crathwohl [1], the knowledge and cognitive process stage of discovering opportunities is one of evaluation. Evaluation requires ability to judge, check and critique the value of a situation and resources for a given purpose [1]. Regarding the knowledge and cognitive process stage, the action of producing an opportunity refers to the creation of an opportunity [1]. Elements of personal resources and contexts are combined to form a new functional whole, such as a new product, service, organizational method, production method, market or new raw material for a given purpose.

Discovering and creating opportunities requires different stages of ego-development: In order to understand this relationship, it is referred to Kegan's [18] self-development theory. Like Loevinger's theory, this theory views selfdevelopment from a constructivist-developmental psychological perspective and essentially portrays the stages of ego-development as does Loevinger. This helps to clarify mechanisms and structures that are to be sure included in Loevinger's theory, but are not directly described [2]. Selfdevelopment passes through qualitatively different stages characterized by a specific subject-object equilibrium. The subject represents the process of meaning making. One is involved in this and identifies oneself with it, but still cannot identify the process in which one is involved. The object stands for the content of meaning making, something a person can identify, reflect, control, change, and to which she can consciously relate. The mechanism that underlies selfdevelopment or respectively ego-development is the subjectobject transformation. The subject becomes the object: In the next higher stage of development, the subject of the previous developmental stage becomes the object [19 p. 37]. The subject-object transformation refers to a person's relations to herself, others and the world. The transformation represents not only a change in form, but also in contents.

In the following, Loevinger's ego-development stages are related to stages of Kegan's self-development model. Since developmental stages E5, E7 and E9 are intermediate stages of subject-object equilibrium, they are not included in the table [18 p. 146-147f.]. Relations to the world, others and oneself are represented not only for subject- but also for object-status, giving respectively three subject- and object categories per developmental stage.

Table 2. Subject-object equilibrium according to Kegan and corresponding stages of ego-development according to Loevinger [cf. also 2].

\begin{tabular}{|c|c|c|c|c|}
\hline $\begin{array}{l}\text { Stage of ego-development } \\
\text { (Loevinger) }\end{array}$ & $\begin{array}{l}\text { Stage of self-development } \\
\text { (Kegan) }\end{array}$ & Subject What steers me? & Object What can I steer? & $\begin{array}{l}\text { Structure of } \\
\text { framework }\end{array}$ \\
\hline E4 Conformist & S3 Interpersonal self & $\begin{array}{l}\text { - Abstractions (e.g. proposition, value) } \\
\text { - Mutuality (e.g. reciprocity) } \\
\text { - Inner states (e.g. Self-consciousness) }\end{array}$ & $\begin{array}{l}\text { - Concrete (e.g. data), } \\
\text { - Point of view (e.g. role concept) } \\
\text { - Durable dispositions (e.g. needs) }\end{array}$ & $\begin{array}{l}\text { Cross- } \\
\text { categories }\end{array}$ \\
\hline E6 Conscientious & S4 Institutional self & $\begin{array}{l}\text { - Abstract systems (e.g. ideology), } \\
\text { - Institution (e.g. relationship regulating } \\
\text { forms), } \\
\text { - Self-authorship (e.g. self-regulation) }\end{array}$ & $\begin{array}{l}\text { - Abstractions } \\
\text { - Mutuality } \\
\text { - Inner states }\end{array}$ & System \\
\hline E8 Individualist & S5 Inter-individual self & $\begin{array}{l}\text { - Dialectical (e.g. paradox) } \\
\text { - Inter-institutional-ization (e.g. } \\
\text { relation-ship between forms) } \\
\text { - Self-Transformation (e.g. } \\
\text { interpenetration of self and } \\
\text { - other) }\end{array}$ & $\begin{array}{l}\text { - Abstract systems, } \\
\text { - Institution } \\
\text { - Self-authorship }\end{array}$ & Trans-system \\
\hline
\end{tabular}

S3 Interpersonal Self A person who has developed an interpersonal self is steered by relationships and expectations of relevant reference persons. Needs and interests can only be reflected in this developmental phase. Interpersonally, a person in this stage can subordinate her needs and interests to the needs of others. She can think abstractly and is selfreflective. [18]

S4 Institutional Self A person in this stage can develop abstract systems consisting of relationships between abstractions. This developmental phase is characterized by a self-governing system through which a person's actions are determined. She is in a position to steer relationships and reflect the expectations of others. These are now objects for her. The rules she creates for her actions are derived from her internal system. She can look at her self-consciousness and reflect it. [18]

S5 Inter-Individual Self In this stage a person is able to recognize her own identity and ideology and to examine it. She is steered by supra-individual values and moves across various self-systems. She can look across systems to learn about similarities that seem at first glance like differences. [18]

If an entrepreneurial opportunity should be discovered, the structure of the framework for making meaning from experience is one in which supply and demand are represented as cross-categories (subject). They are durable categories subordinated to interactions between them [19 pp. 29-30]. Because the would-be-entrepreneur is able to reflect durable categories (object), here supply and demand, she relates demand and supply to each other. The resulting 
abstractions are propositions in terms of relationships between demand and supply. The following example illustrates these propositions: If there is demand for a service, but supply is inadequate, the identified inadequate supply of this service can be corrected by developing new means, ends, or means-ends relationships. Combined with subjective expectation values, this can be a discovered opportunity. The question of how demand determines supply, or supply determines demand is relevant and to be reflected in this stage.

In the case of created opportunity, the opportunity must first be created by the entrepreneur acting and reacting in an iterative process. In order to create an opportunity, a person needs to be able not only to look through the cross-category framework of supply and demand, but also look at that framework. This perspective enables the would-beentrepreneur to make this interaction framework an object of reflection. When looking through an interaction framework, the framework is in the subject state, as it forms the structure of the meaning-making process [19]. Only if the subject becomes an object, i.e., can be considered or regarded and reflected, can it be changed. Market equilibrium, represented by the equilibrium relationship of supply and demand, can only be intentionally destroyed if a person makes this relation, market equilibrium an object. She will then be able to transform abstractions as propositions into relationships between propositions in a system [19]. Related to this meaning-making structure is the content that answers the question: Which are the values and rules that create an interaction between supply and demand? The following example clarifies the process of opportunity creation: The creation of self-driving trucks that destroys the relationship between supply and demand for truck-driver training shows that this destruction opens up new opportunities such as, for example, for training in monitoring the digital systems of "smart" trucks. In the case of creating opportunity, the would-be-entrepreneur is able to change the values and rules according to newly developed self-evaluated standards and to separate herself from previously dominant mental preoccupations and structures, such as the demand-supply rule of truck-driver training [20 p. 200].

From discovering to creating opportunities, a transformation of the meaning-making process, an egodevelopment, takes place, because the former subject, the interaction framework, becomes an object of reflection. While in regard to discovering opportunities, a person acts in the frame of lacking manifestations, in the case of creating opportunities she steers the relationship, because here she develops a system that enables her to influence market equilibrium. While the structure of the interacting durable categories (cross-categories) is manifested in the conformist stage (S3: Stage of Interpersonal Self; E4-E5: Conformist/Self-Aware Stage), the capacity to make this interaction the object of reflection is developed in the postconformist stage (S4: stage of institutional self; $\geq$ E6: Conscientious Stage).

Referring to conscious preoccupations which represent a person's current concerns, the theme of opportunities becomes important in the conformist stage (Stage E5: selfaware stage) [16]. The self-aware person is able to see multiple possibilities in situations [16]. This perspective contributes to the increasing subjective importance of the topic of opportunities. The aspect of opportunity changes, however, throughout the various stages of the egodevelopment sequence. As this conscious preoccupation is described more fully at higher stages of ego-development [16 p. 14], theoretically the self-aware stage seems to be, in terms of conscious preoccupations, the minimum stage of egodevelopment for entrepreneurs to discover and exploit opportunities. In order to create opportunities, the would-beentrepreneur needs to change the values and the rules according to newly developed self-evaluated standards, which characterize conscious preoccupations in the Conscientious Stage (E6) [16], which can be subsumed under the post-conformist stage.

Correspondingly, it can be argued that the identity (Self-asObject) produced by the "ego" differs depending on how entrepreneurs discover or create opportunities: While discovering provides opportunities for imitators, creating produces opportunities for innovators [cf. also 13 p. 6]. Depending on the type of action, discovering or creating opportunities, different numbers of identities are assumed which are central and salient to the overall self-concept: Innovators, for example, have four central salient identities, while imitators have three, and self-employed professionals, who produce standardized products and a smaller number of novel products than imitators, have just two central identities [39]. Moreover, the formation of identity interacts with these types of acting. The formation of identity can be the result of social construction and/or of the individual's "agentic power" [39 p. 50]. Identity formation as a process of social construction results from structures, situations, social relationships and discourses. Identity formation as intrinsically prospected exploration means that the individual is actively searching for a certain identity. A strong socially constructed and a weak intrinsically prospected entrepreneurial identity can be related to the conformist developmental stage. For the imitator type, the entrepreneur's sense of belonging and security needs seem typical [39]. Needs for social belonging and social approval characterize the conformist stage (Stage: E4) of ego-development. To satisfy their security needs, imitative entrepreneurs are less engaged in innovating products, services or processes. While the constituents of the imitator type's entrepreneurial identity result from social construction, the innovator's identity is usually more intrinsically prospected [39]. The innovator type of entrepreneur is characterized by needs such as "selfactualization/self-realization" [39 p. 90], which characterize the conscientious stage (Stage: E6). "The innovative entrepreneurs often found the business as a means to realize their personal vision of changing the world rather than other less idealistic motives, such as financial security" [39 p. 90]. Self-evaluated standards being part of the post-conformist stage (E6: Conscientious stage), they typically guide the 
thinking and acting of the innovator type in order to create a supply-demand interaction.

Entrepreneurs who create new entrepreneurial opportunities may have higher scores on ego-development than entrepreneurs who recognize a business opportunity that already exists. The different identified cognitive processes and knowledge levels of discovering or developing opportunities correspond with the business perspective emphasizing the different degrees of opportunity innovation. In terms of the structure of the framework, conscious preoccupations, cognitive style and character, the conformist stage, with a minimum level of $\mathrm{E} 4$, is a central stage for entrepreneurs recognizing and exploiting entrepreneurial opportunities. In contrast, the post-conformist stage, with a minimum level of E6, seems to be a more typical level for entrepreneurs creating new business opportunities. If creating entrepreneurial opportunities is assumed able to generate higher growth-rate companies than does recognizing opportunities, the study concludes from a theoretical perspective that higher stages of ego-development, such as a (minimum) level of stage E6, may provide the typical fundamental capacities and relevant foundation for successful entrepreneurship.

\section{Discussion}

The study proposes an entrepreneurial competency model that provides insight about the key behavior that a successful entrepreneur should be able to demonstrate, and the underlying characteristics of a person which result in that behavior.

Entrepreneurial key behaviors can be described on at least two competency, or respectively developmental levels:

Level 1: Competency in recognizing and exploiting (= taking advantage of) opportunities that already exist

Level 2: Competency in producing and exploiting (= taking advantage of) opportunities that did not previously exist

Discovering an entrepreneurial opportunity requires at least the conformist stage of ego-development, and producing an opportunity requires the post-conformist stage.

The model of key entrepreneurial competencies and its underlying characteristics is presented in Figure 1.

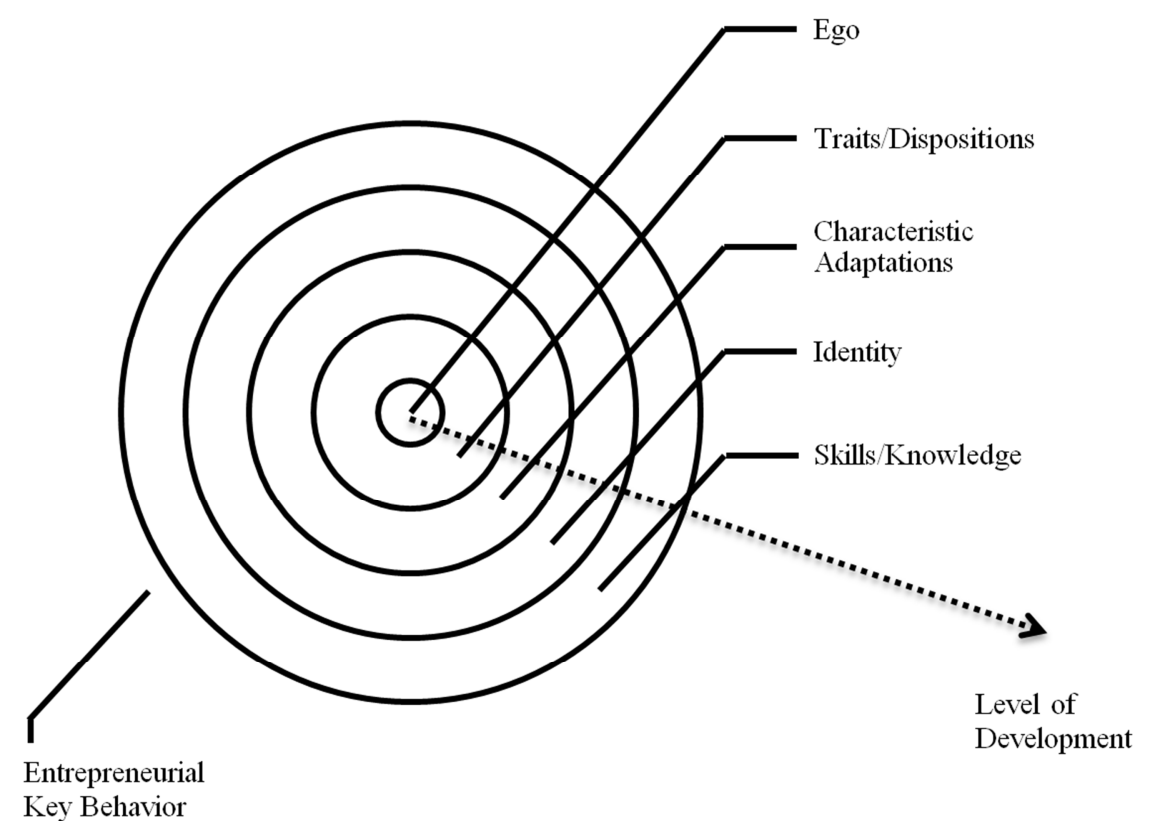

Figure 1. Model of entrepreneurial competencies.

Beyond the circles of underlying entrepreneurial characteristics included in Boyatzis' model, there is a circle of the meaning-making system located in the center of the circle model and regarded as the ego. The ego as the self-as-subject or the meaning-making system produces the "me," the "selfas-object." According to McAdams' [31 p. 30] model of the self-as-object, it is comprised of three levels: (1) dispositional traits, (2) characteristic adaptations representing the characteristic ways people deal with different demands and challenges that life presents them with, such as self-efficacy or competitiveness and (3) life narrative as identity. Referring to our entrepreneurial model, in the center is the self-as-subject, the ego as the meaning-making system. In the following circles we find the circles of the self-as-object, produced by the ego. These are the trait dispositions, motives, characteristic orientations and identity, including the self-image. The parts which form the "me" determine action orientation. They are supplemented in the further circles by so-called personal tools, which enable a would-be-entrepreneur to realize her concerns and goals. Among the tools are skills and knowledge. The circle surrounding skills and knowledge represents the observed key behaviors, actions.

The model is enriched with a developmental dimension as the entrepreneurial ego gradually becomes more complex and associated entrepreneurial behaviors and skills are increasingly practiced. Depending on level of the 
entrepreneurial key behaviors, underlying fundamental capacities vary in terms of our example of egodevelopment and correspondingly of identity complexity and formation: More complex frames of reference interact with awareness of the topic of entrepreneurial opportunities, with a more complex and intrinsically prospected identity, a higher level of entrepreneurial key behavior and entrepreneurial success.

An entrepreneurial competency model is proposed that gives insight about the key behavior of recognizing/producing and exploiting entrepreneurial opportunity which a successful entrepreneur should be able to demonstrate, and a person's underlying characteristics. The underlying characteristics consist of the self and personal tools. The self comprises the self-as-subject, the ego as a meaning-making process, and the self-as-object, with dispositional traits, characteristic adaptations and identity. Personal tools include skills and knowledge. The model that consists of concentric circles is enriched with a developmental dimension.

\section{Conclusion}

This theoretically developed model of entrepreneurial competencies shows that entrepreneurial competency development refers not only to improvement of skills and acquisition of knowledge. It also results in a change of the ego, traits, characteristic adaptations and identity that are expected to affect behavior [15]. Promoting entrepreneurial skills can be regarded as a process of entrepreneurial development that besides learning also includes other processes inherent in their development. According to this model, entrepreneurial development should address the ego, motives and traits, characteristic adaptations and identity, as well as skills and knowledge. Ego-development could be a key motor for developing the personality-related factors of the other circles. For example, ego-development contributes to modifying expressions of traits to produce a more mature form. Such a process of ego-development can be regarded as time-consuming and cannot be advanced via so-called shortterm learning 'nuggets'.

Finally, the study must also be considered in light of its limitations. Given the theoretical character of the analysis and synthesis, future research should empirically test this model using data samples from different regions and cultures. Besides testing this model, inductive methods should be employed to determine whether there are further categories of key entrepreneurial behavior which should be included in the model.

\section{Competing Interests}

The authors declare that they have no competing interests.

\section{Acknowledgements}

This project has received funding from the European
Union's Horizon 2020 research and innovation programme under grant agreement No 645441. The authors would like to thank the European Commission for funding this research and innovation project.

\section{References}

[1] Anderson, L. W. (Ed.), Krathwohl, D. R. (Ed.), Airasian, P. W., Cruikshank, K. A., Mayer, R. E., Pintrich, P. R., Raths, J., \& Wittrock, M. C. (2001). A taxonomy for learning, teaching, and assessing: A revision of Bloom's Taxonomy of Educational Objectives. New York: Longman.

[2] Binder, T. (2014). Persönlichkeitsentwicklung und Beratungskompetenz: Ich-Entwicklung von Beratern und Führungskräften im Rahmenvon Weiterbildungsprogrammen. Dissertationsschrift zur Erlangung des akademischen Grades Doktor der Philosophie (Dr. phil.). Freie Universität Berlin. Fachbereich Erziehungswissenschaften und Psychologie. Berlin.

[3] Bird, B. (1995). Towards a theory of entrepreneurial competency. Advances in Entrepreneurship, Firm Emergence and Growth, 2 (1), 51-72.

[4] Boyatzis, R. E. (2008). Competencies in the 21st century, The Journal of Management Development, 27 (1), 5-12.

[5] Boyatzis, R. E. (1982). The competent manager: A model for effective performance. New York: John Wiley \& Sons.

[6] Brandstätter, H. Personality aspects of entrepreneurship: A look at five meta-analyses. Personality and individual differences, 2011, 51 (3), pp. 222-230.

[7] Brush, C. G., de Bruin, A. \& Welter, F. (2009). A genderaware framework for women's entrepreneurship. International Journal of Gender and Entrepreneurship, 1 (1), 8-24.

[8] Bullough, A, de Luque, M. S., Abdelzaher, D. \& Heim, W. (2015). Developing Women Leaders Through Entrepreneurship Education and Training. Academy of Management Perspectives, 29 (2), 250-270.

[9] Davis, M. H., Hall, J. A. \& Mayer, P. S. (2016). Developing new measure of entrepreneurial mindset: reliability, validity and implications for practitioners. Consulting Psychology Journal: Practice and Research, 68 (1), 21-48.

[10] Day, D. V., Harrison, M. M., \& Halpin, S. M. (2009). An integrative approach to leader development: Connecting adult development, identity, and expertise. New York: Taylor \& Francis.

[11] Eckhardt, Jonathan, T. \& Shane, Scott, A. (2003). Opportunities and Entrepreneurship. Journal of Management 200329 (3) 333-349.

[12] Göbel, S. (1998) Persönlichkeit, Strategien und Erfolg. In M. Frese (Ed.), Erfolgreiche Unternehmensgründer [Schriftenreihe: Wirtschaftspsychologie] (pp. 99-122). Göttingen: Verlag für Angewandte Psychologie.

[13] Grichnik, D. (2006). Die Opportunity-Map der internationalen Entrepreneurshipforschung: Zum Kern des interdisziplinären Forschungsprogramms. Zeitschrift für Betriebswirtschaft 76 (12), $1-31$.

[14] Helsing, D. \& Howell, A. (2013). Understanding Leadership from the Inside out: Assessing Leadership Potential Using Constructive-Development Theory. Journal of Management Inquiry, 23 (2):186-204. 
[15] Hoang, H., \& Gimeno, J. (2007). Becoming a Founder: How Founder Role-Identity Affects Entrepreneurial Transitions and Persistence in Founding. INSEAD Business School Research Paper, (2007/46).

[16] Hy, X. H., \& Loevinger, J. (1996). Measuring Ego Development. Second Edition. Mahwah, NJ: Lawrence Erlbaum Associates.

[17] James, W. (1963). Psychology. Greenwich: Fawcett.

[18] Kegan, R. (1994). In over our heads. The mental demands of modern life. Cambridge.

[19] Kegan, R. (2000). What "Form" transforms? A ConstructiveDevelopmental Approach to Transformative Learning. In J. Mezirow (Ed.), Learning as Transformation. Critical Perspectives on a Theory in Progress (pp. 35-69). San Francisco, CA: Jossey-Bass.

[20] Kegan, R. (2001). Competencies as Working Epistemologies Ways We Want Adults to Know. In: Rychen, D. S., Salganik, L. H. (Hg.): Defining and selecting key competencies. Seattle et al.: Hogrefe \& Huber, S. 192-204.

[21] Kirzner, I. (1973). Competition and entrepreneurship. Chicago: University of Chicago Press.

[22] Leutner, F., Ahmetoglu, G., Akhtar, R. \& Chamorro-Premuzic, T. (2014). The relationship between the entrepreneurial personality and the Big Five personality traits. Personality and Individual Differences, 63, 58-63.

[23] Lienig, Andreas (2017). Komplexität und Entrepreneurship. Komplexitätsforschung sowie Implikationen auf Entrepreneurship-Prozesse. Wiesbaden: Springer Gabler.

[24] Loevinger, J. (1976). Ego Development: Conceptions and Theory. San Francisco: Jossey-Bass.

[25] Loevinger, J. (1997). Stages of personality development. In R. Hogan, J. Johnson \& S. Briggs (Eds.), Handbook of Personality Psychology (pp. 199-208), San Diego, CA: Academic Press.

[26] Loevinger, J. (1998). History of the sentence completion test (SCT) for ego development. In J. Loevinger (Ed.), Technical foundations for measuring ego development. (pp. 1-10). Mahwah, NJ: Lawrence Erlbaum.

[27] Makhbul, Z. M., \& Hasun, F. M. (2011). Entrepreneurial Success: An Exploratory Study among Entrepreneurs. International Journal of Business and Management, 6 (1), 116-125.

[28] Man, T. W., Lau, T. \& Snape, E. (2008). Entrepreneurial competencies and the performance of small and medium enterprises: an investigation through a framework of competitiveness. Journal of Small Business and Entrepreneurship, 21 (3), 257-276.

[29] Martin, B. C., McNally, J. J., \& Kay, M. J. (2013). Examining the formation of human capital in entrepreneurship: A metaanalysis of entrepreneurship education outcomes. Journal of Business Venturing, 28 (2), 211-224.

[30] Maturana, H. (2000). The Nature of the Law of Nature. Systems Research and Behavioral Science (17), 459-468.

[31] McAdams, D. P. (1998). Ego, trait, identity. In P. M. Westenberger, A. Blasi, \& L. C. Cohn (Eds.), Personality development: Theoretical, empirical, and clinical investigations of Loevinger's conception of ego development (pp. 27-38). Hillsdale: Lawrence Erlbaum.

[32] McClelland, D. C. (1951), Personality, William Sloane Associates, New York, NY.

[33] McLaughlin, E. B. (2012). An emotional business: The role of emotional intelligence in entrepreneurial success. Dissertation. University of Texas.

[34] Mezirow, J. (2000). Learning to think like an adult. In J. Mezirow (Ed.), Learning as Transformation. Critical Perspectives on a Theory in Progress (pp. 1-33). San Francisco, CA: Jossey-Bass.

[35] Mitchelmore, S. \& Rowley, J. (2010). Entrepreneurial competencies: a literature review and development agenda. International Journal of Entrepreneurial Behavior \& Research, 16 (2), pp. 92-111. doi: 10.1108/13552551011026995.

[36] Novy, D. M. (1993). An investigation of the progressive sequence of ego development levels. Journal of Clinical Psychology, 49, 332-338.

[37] Peris Bonet, F., Rueda Armengot, C. \& Galindo Martín, M. Á. (2011). Entrepreneurial success and human resources. International Journal of Manpower, 32 (1), 68-80.

[38] Piacentini, M. (2013). Women Entrepreneurs in the OECD: Key Evidence and Policy Challenges. OECD Social, Employment and Migration Working Papers, No. 147, OECD Publishing. doi: 10.1787/5k43bvtkmb8v-en.

[39] Poudel, K. P. (2014). A discourse on entrepreneurial identity: three essays. Electronic Theses and Dissertations. Paper 1757.

[40] Rauch, A. \& Frese, M. (2007). Let's put the person back into entrepreneurship research: A meta-analysis on the relationship between business owners' personality traits, business creation, and success. European Journal of Work and Organizational Psychology, 16 (4), 353-383.

[41] Schumpeter, J. (1934). Capitalism, socialism, and democracy. New York: Harper \& Row.

[42] Schumpeter, J. (1912/2006). Theorie der wirtschaftlichen Entwicklung, Berlin 1912; Neuausgabe hrgg. von Jochen Röpke und Olaf Stiller, Berlin 2006.

[43] Shane, S., \& Venkataraman, S. (2000). The promise of entrepreneurship as a field of research. Academy of Management Review 25 (1), 217-226.

[44] Spencer, L. M. \& Spencer, S. M. (1993). Competence at work. Models for superior performance. New York: Wiley \& Sons.

[45] Spinosa, Ch., Flores, F., \& Dreyfus, H., (1999). Disclosing new worlds: Entrepreneurship, democratic action, and the cultivation of solidarity. Cambridge, MA: MIT Press.

[46] Unger, J. M., Rauch, A., Frese, M. \& Rosenbusch, N. (2009). Human capital and entrepreneurial success: A meta-analytical review. Journal of Business Venturing, 26, 341-358.

[47] Venkataraman, S. (1997). The distinctive domain of entrepreneurship research: An editor's perspective. In J. Katz \& R. Brockhaus (Eds.), Advances in entrepreneurship, firm emergence and growth: Vol. 3, 119-138. Greenwich, CT: JAI Press. 